\title{
Comparative study on high-strength structural elements and CNT additions.
}

\author{
Dimensionamiento comparativo de elementos estructurales de alta resistencia frente a \\ adiciones de CNT. \\ Jose Luis Fraga (Main Author) \\ Delegate of ELSAN (OHL Group), Spain. \\ jfraga@ohl.es
}

Jose María del Campo (Contact Author)

Universidad Politécnica de Madrid, Depto Ingenieria Civil.

Alfonso XII, 3 y 5 - 28014 Madrid fono +34 3367730

josemaria.delcampo@upm.es

Juan Ángel García

Universidad Alfonso X El Sabio, Madrid.

jolirgar@uax.es

\section{Félix Escolano}

Universidad Politécnica de Madrid, Depto Ingenieria Civil.

felix.escolano@upm.es

Manuscript Code: 597

Date of Acceptance/Reception: 01.08.2016/25.03.2015

\begin{abstract}
Carbon Nanotubes (CNT) show extraordinary properties such as high strength and stiffness, the highest among known materials. This is what makes them potential candidates for concrete reinforcement. This paper explores the applicability of CNT in cementitious matrices comparing results derived from high-strength concrete and conventional concrete, as well as conventional concrete. For the execution of this research, and in order to analyze cement mortars with additions when compared to high-strength concrete, different types of CNT have been depicted and selected. After the characterization of different cement pastes obtained, structural elements have been measured. This analysis leads us to the conclusion that the most suitable mechanical strengthening agent for laboratory scale small samples is the use of CNT, since we do not detect significant differences between the structural elements dimensions and high-strength concrete regarding pastes with CNT.
\end{abstract}

Keywords: nanotubes, carbon, concrete strength, additions, structures.

Resumen

Los nanotubos de carbono (CNT) poseen propiedades extraordinarias como su elevada resistencia y rigidez, las más elevadas de los materiales conocidos. Estas les hacen candidatos potenciales como material de refuerzo de hormigón. Este trabajo profundiza en la aplicabilidad de los CNT en matrices cementantes comparando los resultados con hormigones de alta resistencia, así como con hormigones convencionales. Para la realización de este trabajo, se han seleccionado y caracterizado diferentes tipos de CNT con el fin de estudiar morteros de cemento con adiciones comparándolos con hormigones de alta resistencia. Tras la caracterización de las diferentes pastas de cemento obtenidas, se han dimensionado elementos estructurales. Con estos estudios se concluye que, sólo se considera apropiada la utilización de los CNT como agentes de refuerzo mecánico, para muestras pequeñas a escala de laboratorio, ya que no se aprecian diferencias notables entre las dimensiones de los elementos estructurales con hormigones de alta resistencia respecto a los hormigones con CNT.

Palabras clave: nanotubos, carbono, resistencia del hormigón, adiciones, estructuras.

State of the art

Since 1939, with the commercial development of the first transmission electron microscopy (TEM), an internal morphology and texture of the carbon filaments has been achieved. In 1952, a group of Russian researchers provided the first proofs of carbon tubes' formation (Lukyanovich, 1952), most likely multi-walled (MWCNTs), although the TEM resolution at that time did not allow distinguishing the number of layers. Hence, the discovery of MWCNTs has been typically linked to Sumio lijima, who characterized a new carbon allotrope through high resolution microscopy which he called carbon nanotube (CNT) (Iijima, 1991). Two years later and independently, Donal Bethue along with IBM partners discovered the single-wall carbon nanotubes (SWCNTs) (Georgakilas et al., 2002). 
CNTs are carbon allotropes whose molecular structure can be viewed as mixed cylinders made of rolled graphene layers (Saito, Dresselhaus, \& Dresselhaus, 1998). There are two types of CNTs which differ depending on the graphene layers which, if there is only one layer of graphene, then it is called SWCNTs, whereas they are called graphene MWCNTs if they are composed by concentrically arranged walls. The diameters of these structures range from 4 to 50 $\mathrm{nm}$ in MWCNTs, and from 0.4 to $10 \mathrm{~nm}$ in SWCNTs, while the CNTs diameters are nanometric and their typical length reaches micrometers, having even synthesized several centimeters of the CNT length (Zhu et al., 2002)(Zheng et al., 2004)(Ferro, Tulliani, \& Musso, 2011). Therefore, CNTs show a high connection both in length and diameter, typically 1000 and able to exceed 107, which give them a quasi-one-dimensional structure (1D). Multi-walled CNTs can be up to hundreds of layers, the interlaminar spacing is $0.34 \mathrm{~nm}$ (Popov, 2004). Stable forces separations between adjacent layers are of Van der Waals type. The ends of the CNT may be open or be covered by a fullerene molecule (Saito et al., 1998), that is, an allotrope of closed, spheroid and empty carbon structure composed by pentagonal and hexagonal sides. These structures were discovered (Kroto, Heath, O’Brien, Curl, \& Smalley, 1985) six years before the discovery of MWCNTs by lijima. There is a wide range of CNT with a unique combination of parameters. Each wall may be distinguished by its chiral angle, diameter, and length, as well as by the combination of multiple MWCNTs walls that result in a greater differentiation (Popov, 2004).

The main interest in the CNTs is mainly due to its wide spectrum of exceptional properties: from the higher strength and stiffness of all known materials so far, to some highly unusual properties of electron transport and a large chemical robustness, which derived from its geometry and chemical structure and confers a unique potential in a variety of very different applications (Martínez, M. R., Ganzer, J. R., \& Huertas, 2007). Many applications have already been successfully commercialized, such as the mobile phones lithium-ion batteries, electrically conductive fillers in plastics and polymer composites for sporting goods (De Volder, Michael F. L. Sameh H. Tawfick \& Hart, 2013).

The excellent mechanical properties of CNTs make them potential candidates as reinforcing material for concrete. The MWCNTs are preferred for research in the reinforcement of concrete, as they are less expensive to synthesize than SWCNTs (Li Wang, Pei Ming, Zhao, Xiaohua, 2005), show a tensile strength from 11 to $63 \mathrm{GPa}$, approximately 100 times higher than steel, the material most widely used for concrete reinforcement being 6 times lighter with a Young's modulus ranging from 0.8 to $0.9 \mathrm{TPa}$, and a prior lengthening of $12 \%$, that is to say, 60 times higher than the steel one (Yu, 2000). The SWCNTs have a higher Young's modulus and ductility even greater, while the values of tensile strengths are slightly lower (Min Feng Yu, S., Arepalli, \& Ruoff, 2000), thus, the integration of CNT into concrete has the potential to increase the tensile strength of the concrete and its ductility. Furthermore, the high specific value of CNT area, together with their outstanding mechanical properties, can significantly reduce the porosity of concrete, and increase resistance to crack propagation distributed in the cement matrix, acting the CNT as bridges between the holes and cracks (Li Wang, Pei Ming, Zhao, Xiaohua, 2005).

\section{Description of the problem}

CNTs are not ideal structures and the reactivity of their walls is mainly due to the presence of defects such as holes, Stone-Wales defects, etc. Often, CNTs undergo functionalization treatments. The CNTs functionalization increases their polarity, improving solubility and easing their dispersion; CNTs are treated through chemical methods with oxidizing compounds, typically strong acids that functionalize the nanotubes wall surfaces, especially creating carboxylic acid groups and hydroxyl groups covalently bonded to their surface. The CNT functionalization is carried out with the purpose of using the dispersion method which must ensure not only a uniform distribution of the CNT in the matrix, but also good adhesion between the CNT and the products of the matrix, as the latter is necessary to ensure an efficient transfer of matrix loads to the CNT. The research on CNT-concrete composite materials is at an early stage since clear improvements after integrating CNTs to cementitious materials have been demonstrated (Li Wang, Pei Ming, Zhao, Xiaohua, 2005) (Li, Wang, \& Zhao, 2007), although these results are still to be put into practice. Further research on functionalization and dispersion methods for carbon nanotubes and adhesion of CNTs to the cementitious matrix is still needed and also needs a more economic synthesis of CNT in order to perform a real implementation of CNT-reinforced concrete. Therefore, this paper explores the applicability of high purity CNT and industrial grade compared with high-strength concrete and conventional concrete.

\section{Materials}

\section{CNTs Selection}

Initially, and because it offers a wide range of CNTs, only the company NanoAmor (Nanostructured \& Amorphous Materials Inc.) was selected as a CNT provider. MWCNTs were acquired with different characteristics. The first choice 
was three unfunctionalized CNT, two functionalized with carboxylic groups and two hydroxyl groups (-OH). After the characterization of the CNT NanoAmor company and making cement pastes with $0.5 \%$ of CNT added to the concrete, it was decided to perform the characterization of functionalized CNT with -OH groups (see Table 1), in order to prepare cement test tubes with $0.5 \%$ from the above mentioned CNTs.

Table 1. Acquired CNT characteristics. Own Elaboration, 2014.

\begin{tabular}{|c|c|c|c|c|c|}
\hline \multirow[b]{2}{*}{ Reference Code } & \multirow[b]{2}{*}{ Description } & \multirow[b]{2}{*}{ Company } & \multirow[b]{2}{*}{ Details } & \multicolumn{2}{|c|}{ Functionalization } \\
\hline & & & & $-\mathrm{OH}$ Content & $\begin{array}{l}\% \text { at. Of functionalized } \\
\text { carbon over the surface }\end{array}$ \\
\hline CNT-1 & $\begin{array}{l}\text { MWNT-OH (95+\%) } \\
\text { OD 50-80 nm }\end{array}$ & \multirow{2}{*}{ NanoAmor } & $\begin{array}{c}\phi_{\text {Interior: }}:-15 \mathrm{~nm} \\
\mathrm{~L}: 10-20 \mu \mathrm{m} \\
\text { SSA: } \sim 40 \mathrm{~m}^{2} / \mathrm{g}\end{array}$ & $1-7 w t \%$ & $21-26 \mathrm{~mol} \%$ \\
\hline CNT-2 & $\begin{array}{c}\text { MWNT-OH } \\
(95+\%) \\
\text { OD } 10-20 \mathrm{~nm} \\
\end{array}$ & & $\begin{array}{c}\phi_{\text {Interior: }} 5-10 \mathrm{~nm} \\
\text { L: } 10-30 \mu \mathrm{m} \\
\text { SSA: } \sim 200 \mathrm{~m}^{2} /\end{array}$ & $1-7 w t \%$ & $21-26$ mol\% \\
\hline CNT-3 & $\begin{array}{l}\text { MWNT-OH (95wt\%) } \\
\text { OD >50 nm }\end{array}$ & Cheap Tubes & $\begin{array}{c}\phi_{\text {Interior }}: 5-15 \mathrm{~nm} \\
\text { L:10-20 } \mu \mathrm{m} \\
\text { SSA: } \sim 60 \mathrm{~m}^{2} / \mathrm{g}\end{array}$ & $0,5-1$ wt $\%$ & \\
\hline CNT-4 & $\begin{array}{l}\text { MWNT-OH (95wt\%) } \\
\text { OD > 50nm }\end{array}$ & Chengdu Organic & $\begin{array}{c}\phi_{\text {Interior: }} 5-15 \mathrm{~nm} \\
\text { L: } 10-20 \mu \mathrm{m} \\
\text { SSA: } \sim 40 \mathrm{~m}^{2} / \mathrm{g}\end{array}$ & 0,71 wt $\%$ & $8-10 \mathrm{~mol} \%$ \\
\hline
\end{tabular}

The characterization of the CNT was performed by using the scanning electron microscopy (SEM) to confirm the conformational characteristics of acquired CNTs, Fourier Transform Infrared Spectroscopy, FT-IR to determine the presence of functional groups generated in the surface of CNT, Thermogravimetric Analysis (TGA) to analyze the process of thermal degradation of the CNT and X-ray Photoelectron Spectroscopy (XPS) for chemical characterization of the sample surfaces.

\section{CNTs Characterization}

\section{Scanning Electron Microscope}

Figure 1 shows some of the images taken with the Scanning Electron Microscope. In samples we can observe tangles or skeins of CNT aggregates, with dimensions roughly adjusted to the specifications of the suppliers.

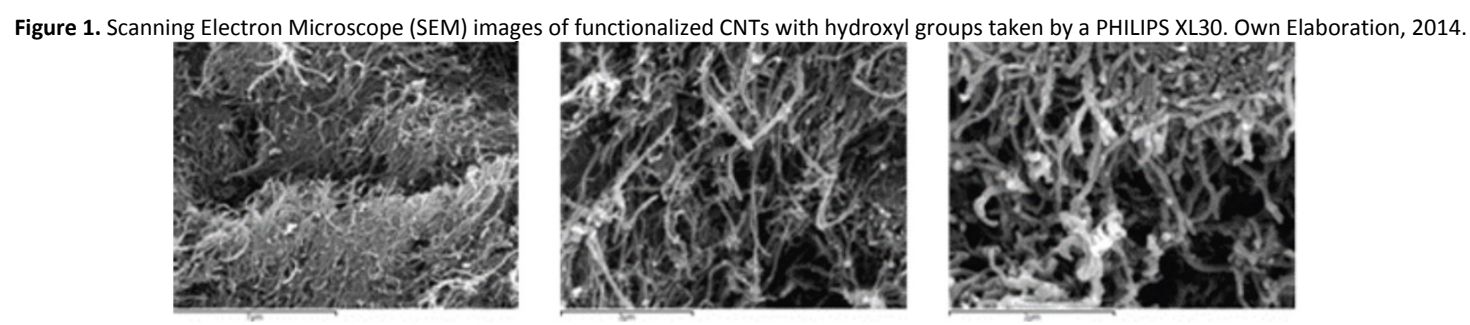

\section{Fourier Transform Infrared Spectroscopy}

FTIR spectra were obtained with a Perkin-Elmer, Spectrum One v. 5.0. model. Potassium bromide tablets were prepared from dried and pounded samples during 24 hours at $110^{\circ} \mathrm{C}$. The measuring range is $4000-450 \mathrm{~cm}-1$. For each spectrum, 10 entries were acquired with a resolution of $4 \mathrm{~cm}-1$. Figure 2 shows infrared spectra of functionalized CNT with hydroxyl groups (-OH). In them, there is a broadband between 3200 and $3600 \mathrm{~cm}-1$ due to the bond vibration frequencies $-\mathrm{OH}$ of water molecule, which may be present as an impurity in the CNT, and the bonds' vibrations anchored to the - $\mathrm{OH}$ surface of carbon nanotubes. Likewise, another band with two peaks centered at 2850 and 2919 $\mathrm{cm}-1$, due to the vibration frequencies of $\mathrm{C}-\mathrm{H}$ bonds, which may be related to the presence of organic impurities. A small change in the curvature at $1734 \mathrm{~cm}-1$ due to the vibration frequencies of the $\mathrm{C}=\mathrm{O}$ bond at the carboxyl group, which also appears at $1635 \mathrm{~cm}-1$, indicates the presence of small amounts of carboxyl groups resulting from the functionalization process. Finally, around 1100 and $1300 \mathrm{~cm}-1$ a number of bands allocated to vibrations of C-O bonds, which are justified by the presence of -OH groups bonded to the CNT surfaces. 
By observing the graphs in Figure 2, we can see that the presence of impurities is higher in functionalized CNT with $\mathrm{OH}$ groups supplied by Chengdu Organic as the bands around $2900 \mathrm{~cm}-1$ are more intense in this product than in others.

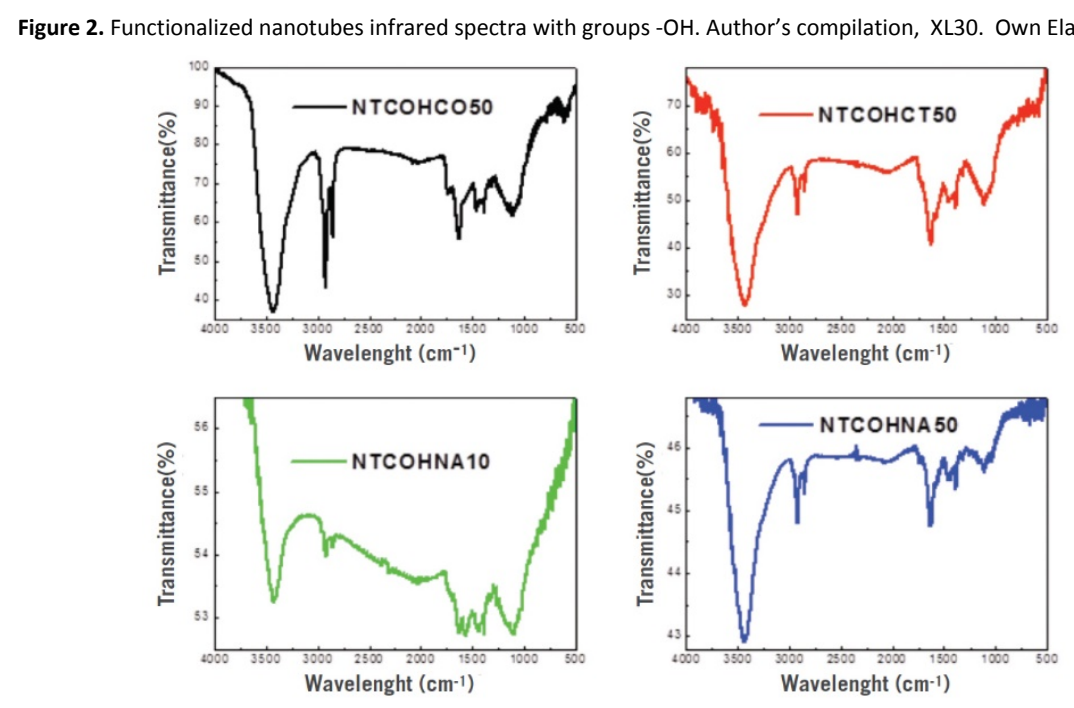

\section{Thermogravimetric Analysis}

Thermogravimetric analyses were performed with a TGA/SDTA 851e of Metler Toledo equipment. Approximately 20 $\mathrm{mg}$ of sample are placed on an alumina boat under a constant air flow of $80 \mathrm{ml} / \mathrm{min}$ and a heating rate of $10{ }^{\circ} \mathrm{C} / \mathrm{min}$ from 25 to $1000^{\circ} \mathrm{C}$. Thermogravimetric analysis was also performed with a program combining constant flow of nitrogen and air at a flow rate $75 \mathrm{ml} / \mathrm{min}$ and a heating rate of $10 \circ \mathrm{C} / \mathrm{min}$.

The program consists of three stages: first, heating from $25^{\circ} \mathrm{C}$ to $800{ }^{\circ} \mathrm{C}$ in a nitrogen atmosphere, something that will quantify the groups containing oxygen atoms that are capable of being oxidized in an inert atmosphere; second, cooling from $800{ }^{\circ} \mathrm{C}$ to $300^{\circ} \mathrm{C}$, also in a nitrogen atmosphere; and last, in an air atmosphere from $300{ }^{\circ} \mathrm{C}$ to $1000{ }^{\circ} \mathrm{C}$, in order to oxidize other substances that had not been oxidized previously.

All four samples exhibited a decomposition rate close to $100 \%$ indicating the high purity of these samples (or the nonpresence of substantial quantities of metal catalyst impurities). As shown in Figure 3, the sample with reference NTCOH-NA-10 (CNT-2) presents an initial decomposition temperature lower with respect to the others, possibly because of the presence of a higher percentage of functionalization in this sample; this fact is also confirmed by a greater width in the representation of the derivative indicating lower or greater functionalization homogeneity.

Figure 3. Thermogravimetric analyses of Functionalized CNTs NTC-OH-CO-50(CNT-4), NTC-OH-CT-50 (CNT-3), NTC-OH-NA-10 (CNT-2) y NTC-OH-NA-50 (CNT-1). Own Elaboration, 2014.
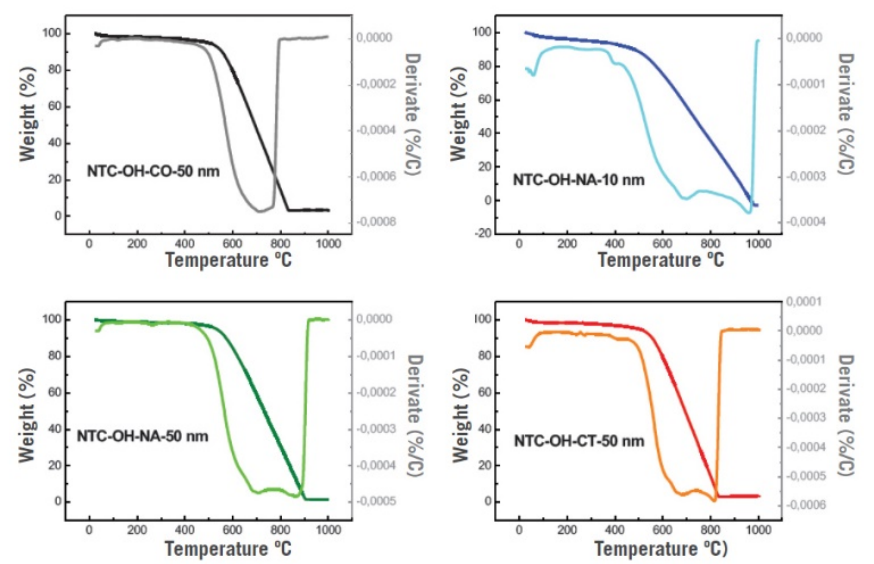
The other three samples with an outer diameter of $50 \mathrm{~nm}$, show very similar graphs, although nanotubes with NTC-50$\mathrm{OH}-\mathrm{CO}$ (CNT-4) reference appear to have a lower percentage of functionalization, for the graph's width of the derivative is lower than the other two samples (between 500 and $800{ }^{\circ} \mathrm{C}$ ).

\section{X-ray Photoelectron Spectroscopy}

The XPS technique permits a chemical characterization of the sample surfaces, approximately $10 \mathrm{~nm}$. Samples analyzed are introduced in an ultra-high vacuum test chamber. While testing, the photoelectrons are detected spreading over the samples' surfaces as the X-rays affect them. In order to characterize CNTs, Axis-ultra equipment, Kratos brand, was used with a monochromatic source of aluminum with a total capacity of $150 \mathrm{~W}$. Upon receiving the samples, they were introduced into the preparation chamber on the same stand, for measurement of samples under the same degassing conditions. From the complete bond energy spectra, it has been concluded that the content of the samples was between $7 \%$ and $9 \%$ in the hydroxyl groups functionalized samples $(-\mathrm{OH})$.

Methodology

\section{Cement Mortar Test Tube Preparation with CNT}

The compatibility of functionalized CNTs with - $\mathrm{OH}$ groups has been analyzed by preparing Portland cement mortar test

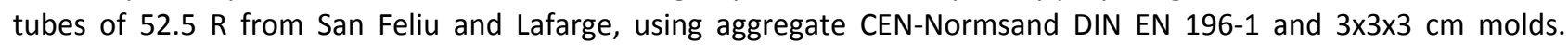
Percentages of $0.5 \%$ CNT were used during performance over the cement. Results from dosages were designed as to arid/cement of 3, water/cement of 0.5 and a CNT percentage of $0.5 \%$ according to cement's weight. Samples were extracted for visual observation and characterization at the age of 2,7 , and 28 days by immersing them into acetone to stop the setting process. Figure 4 shows the images of cement mortar test tubes with unfunctionalized CNTs.

Figure 4. Test tube images at the age of 28 days cement mortar with CNTs (MOR-CNT-1, MOR-CNT-2, MOR-CNT-3, MOR-CNT-4) Own Elaboration, 2014.

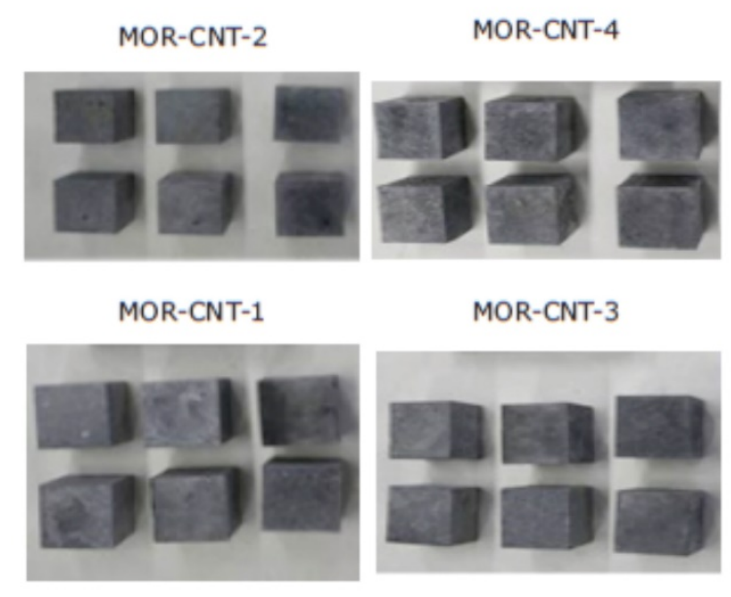

\section{CNTs Dispersion}

CNTs dispersion was made by combining the two common dispersion processes, and ultrasound sonication. The mixture of cement and aggregate is carried out on a dry basis, then the solution was added to the corresponding amount of water in which CNT-OH are dispersed; after mixing the components, these are poured in order to proceed to the molds' filling. This filling is done in three layers of approximately $1 / 3$ of the height of each mold. After placing each layer, they are compacted with 25 strokes evenly distributed over its surface. The filling of the last layer is made with mortar remains. After consolidating the top layer, the sides of the mold are struck smoothly in order to eliminate macro-air bubbles that may create holes in the upper layer. Finally, the test tube is marked at the upper edge of the mold, removing the excess of mortar and kneading its surface until obtaining a perfectly flat and smooth side. Test tubes are unmolded the day after and kept in a humidity chamber at $25^{\circ} \mathrm{C}$ and $95 \%$ humidity to be tested at the age of 7 and 28 days. 


\section{Physico-chemical characterization of cement mortars with CNTs}

\section{Isothermal Titration Calorimetry}

The Isothermal Titration Calorimetry is one of the most used in scientific researches to measure the level of heat released during the hydration reaction of cement methods. This technique not only provides an estimate of the total heat developed during the hydration process, but also provides the instantaneous speed of the released heat at any time. Cement hydration is the result of a transformation from high to low energy state whose energy difference is emitted in the form of heat. The observation of hydration heat in cement can reveal important information about the chemical reactions arising during this process, and the effect that certain additions can produce in cement hydration. The isothermal titration calorimetry testing with CNTs, cement pastes, and mortars were performed to analyze how they affect the cement hydration process. Samples from functionalized CNTs with -OH had a decline in the heat flow and the hydration heat of mortars confirmed the higher effect provoked by CNTs.

\section{Thermogravimetric Analysis of Cement Mortars with CNTs}

Thermogravimetric analysis (TG) of cement mortars with CNT were performed in air flow with a heating rate of $10^{\circ} \mathrm{C}$ per minute from 25 to $1000{ }^{\circ} \mathrm{C}$, grinding a part of the samples of the test tubes in agate mortar and by taking between 20 and $35 \mathrm{mg}$ of these samples to fill the TG crucibles. The decomposition processes of the CNT cement samples were very similar, showing three general decomposition processes. A first process, due to dehydration of the hydrated cement layers, occurs between 50 and $250{ }^{\circ} \mathrm{C}$; a second process involving dehydration of the portlandite $\mathrm{Ca}(\mathrm{OH}) 2$ that occurs between 350 and 600 우 ; and a third stage due to the decarbonation and cement additions of CNT from 600 to $950^{\circ} \mathrm{C}$. The decomposition of CNTs took place in the latest stage and involved an increase in the peak decomposition that occurs in this area of the curves. It can be concluded, as well as in calorimetry tests, that the addition of CNTs does not significantly affect the processes of hydration and thermal decomposition of the various stages of cement.

\section{Mechanical Characterization of Cement Mortars Test Tubes with CNTs}

The characterization of the mechanical properties was performed through compressive strength test of cement pastes test tubes with $30 \times 30 \times 30 \mathrm{~mm}$ CNT, the materials were mixed according to the UNE-EN-196-1:2005 in a press IBERTEST $200 \mathrm{kN}$. Two mixing processes were performed; dry mixing of CNTs with cement, then adding mixing water and CNTs mixing to water and sonication with a BRANSON Sonifier 250 generator during 5 minutes to obtain a uniformly dispersed suspension of nanotubes. The paste was poured into the molds and was vibrated for compaction manually. The samples were unmolded the next day and were cured long enough (28 days) for compressive failure testings according to the UNE-EN-196-1:2005.

Table 2 shows the results of compression tests of cement mortar test tubes with CNTs and the reference test tube without CNTs. As seen from the results shown in Table 2, in the case of functionalized CNTs with -OH groups and an outer diameter of $10 \mathrm{~nm}$ (reference NTC-OH-10-NA), there is an improvement in the values of compressive strength at the age of 28 days, achieving a progress of $17 \%$ with respect to the standard.

Finally, it should be noted that these results exceed those found in the reference section because, although we have already described the use of sonication technique for CNTs dispersion (Wansom, Kidner, Woo, \& Mason, 2006), we have only obtained slight increases in the values of compressive strength tests and nanoindentation (Campillo, Dolado, \& Porro, 2004) (Makar \& Beaudoin, 2003). Nevertheless, there are publications that show similar increases, but always using dispersants and deaerators (Li Wang et al., 2005) (Sobolkina et al., 2012) (Williams, 2008). Contrary to what is shown in the reference, functionalized nanotubes with carboxylic groups produced did not create a significant improvement in cement pastes mechanical properties, probably due to the addition of dispersing agents during tests.

Table 2. Results of compression tests of cement mortars test tubes with $0.5 \mathrm{wt} \% \mathrm{CNT}$, previously dispersed in water through sonication with cement $52.5 \mathrm{R}$. Own Elaboration, 2014.

\begin{tabular}{|c|c|c|c|c|}
\hline \multicolumn{5}{|c|}{ Compressive Strength (MPa) } \\
\hline Test Tube Code & CNT (0.5\%) & 2 days age & 7 days age & 28 days age \\
\hline CEM-0 & - & $38 \pm 3$ & $68 \pm 2$ & $51 \pm 4$ \\
\hline MOR-CNT-1 & CNT-1 & $41 \pm 6$ & $79 \pm 3$ & $60 \pm 4$ \\
\hline MOR-CNT-2 & CNT-2 & $42 \pm 6$ & $80 \pm 2$ & $56 \pm 9$ \\
\hline MOR-CNT-3 & CNT-3 & $45 \pm 5$ & $75 \pm 5$ & $56 \pm 6$ \\
\hline MOR-CNT-4 & CNT-4 & $44 \pm 6$ & $66 \pm 3$ & $46 \pm 9$ \\
\hline
\end{tabular}


The following rules and procedures have been used to determine concrete's properties. Fresh concrete has been analyzed: shear, workability, and plastic viscosity with a 4C Rehometer, once chosen the samples according to their strength and consistency, in a hardened state, the following basic characteristics of concrete were studied: at the age of $1,2,7$, and 28 days to determine their compressive strength (UNE-EN 12390-3:2009), the bending test at the age of 28 days (UNE-EN 12390-5:2009), was also performed a indirect tensile strength test (UNE-EN 12350-6:2009) study of petrography, to determine Young's modulus at the age of 28 days (UNE-EN 12390-13:2014) autogenous and drying shrinkage test (UNE-EN 1367-4:2009) and water's penetration depth under pressure (UNE-EN 12390-8:2009), thus determining the density of fresh concrete (UNE-EN 12350-6:2009).

\section{HSC Dosage}

High strength concrete is defined as the one whose characteristic compressive strength at the age of 28 days in cylindrical test tubes exceeds $45 \mathrm{MPa}$. The fundamental factor for achieving high-strength concrete is the watercement ratio, as it should be about 0.4 or less (De la Rosa, 2004). The definition of the base formulation has been Cement: Cem 52,5 R "CEMEX", Silica fume from Undensified Ferroatlantica (La Coruña), Fly ash from Andorra thermal power station, Superplasticizers: Sika Viscocrete 3425 and Glenium ACE 425, Gravel 6/12 from Alhama International Porphyry in Murcia and Fine Aggregate 0/4 from Alhama International Porphyry (Murcia)

\section{HSC Design and Characterization}

Concrete design is based on tests performed with equivalent mortars, being evaluated their compression strength capacity at the age of $1,2,7$, and 28 days, and their workability according to UNE standards. To this aim, the volume of concrete at 65 liters per mixture for a total of 4 mixtures and 2 mixtures per each dosage. The amount of material used per mixture in $\mathrm{kg}$ was shown in Table 3 and the percentage of each component has been for HSC ref: Watercement ratio of $0,3,4 \%$ of Additive, Cement $52, \mathrm{R}, 10 \%$ of Ashes an $8 \%$ of Silica Fume. Once the HSC test tubes have been manufactured, their mechanical characterization has also been performed, obtaining enhanced results with regard to the HSC workability (as stated in Table 4).

\begin{tabular}{lc}
\multicolumn{1}{c}{ Mable 3. Dosage based on cylindrical test tubes $100 \times 150 \mathrm{~mm}$ of HSC. Own Elaboration, 2014.} \\
\hline Crushed stone 6/12 & $\mathrm{Kg} / \mathrm{m}^{3}$ \\
\hline Sand 0/4 & 363 \\
\hline Cement & 562 \\
\hline Water & 510 \\
\hline
\end{tabular}

\begin{tabular}{|c|c|}
\hline Test Tube & HSC-ref \\
\hline Ystress (Pa) & 63 \\
\hline $\mathrm{Pv}(\mathrm{Pa} * \mathrm{~s})$ & 1118 \\
\hline Wk (mm) & 550 \\
\hline T500 (s) & 24.4 \\
\hline Cs 1 Day age (MPa) & $44.5 \pm 0.16$ \\
\hline Cs2 Days age (MPa) & $62.02 \pm 0.44$ \\
\hline Cs7 Days age (MPa) & $89.00 \pm 0.37$ \\
\hline Cs 28 Days age (MPa) & $116.05 \pm 0.28$ \\
\hline
\end{tabular}

Table 5. Mechanical characterization of cylindrical test tubes $100 \times 150 \mathrm{~mm}$ of mortars with CNT at industrial grade (IND) and high-purity (AP). Own Elaboration, 2014.

\begin{tabular}{ccccc}
\hline Test Tube & Wk $(\mathrm{mm})$ & Rc 1 día (Mpa) & Rc 2 días (Mpa) & Rc 7 días (Mpa) \\
\hline HSC & 550 & $44.5 \pm 0,16$ & $62.02 \pm 0,44$ & $89.00 \pm 0,37$ \\
\hline H-CNT-1 & 147 & $45 \pm 5$ & $56 \pm 6$ & $69.0 \pm 2.9$ \\
\hline H-CNT-2 & 255 & $41 \pm 6$ & $60 \pm 4$ & $73.2 \pm 0,7$ \\
\hline H-CNT-3 & 156 & $36.6 \pm 0.4$ & $48.9 \pm 1,7$ & $77.0 \pm 1,9$ \\
\hline H-CNT-4 & 137 & $44 \pm 6$ & $46 \pm 9$ & $76.1 \pm 2,2$ \\
\hline
\end{tabular}


Finally, an equivalent control over mortar and dosage has been carried out with $0.5 \%$ of CNT in order to collate results. According to the results shown in Table 7, we notice a significant reduction in the workability of CNT test tubes; as the HSC is developed, the effect of improving the nanotubes mechanics can no longer be seen, resulting in values lower than the pattern. It can be justified by assuming that it worked with larger sample volumes where there are intense agglomeration problems.

The structural element has been defined below from the results of compressive strength at the age of 28 days, taking into consideration the rules currently in force in Spain (Comisión Permanente del Hormigón, 2011) (Comisión Permante de Normas Sismoresistentes. Ministerio de Fomento, 2002) (VV.AA., 2016). A portal has been designed for a linear work road, which supports a $270 \mathrm{kN}$ point load on the left pillar, and a $1220 \mathrm{kN}$ point load on the right pillar, the beam that rests on these pillars carries a distributed load of $145 \mathrm{kN} / \mathrm{m}$ (see Figure 5).

Figure 5. Structural diagram of the portal and overloading pressure supported. Own Elaboration, 2014

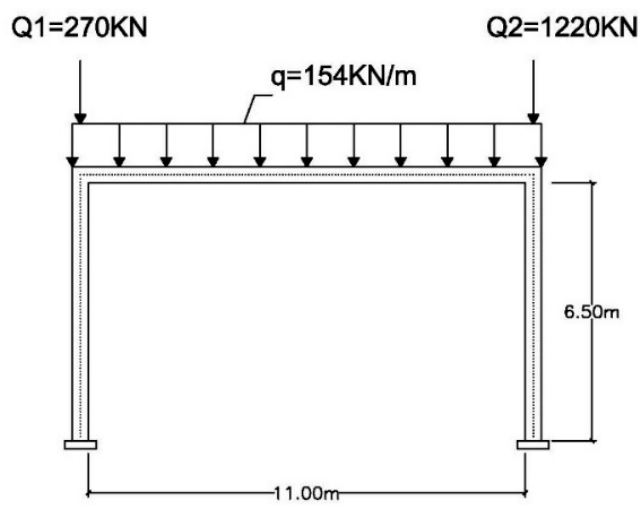

In Table 6 the final stresses that support the pillars of the above mentioned structure and its dimensions are detailed, as well as the reinforced concrete resulting from a first calculation through conventional concrete, high-strength concrete, and concrete with CNTs.

\begin{tabular}{|c|c|c|c|c|c|c|c|}
\hline \multicolumn{4}{|c|}{ Calculation Values } & \multicolumn{4}{|c|}{ Materials } \\
\hline $\mathrm{Nd}$ & & & $1944,94 \mathrm{kN}$ & Passive Steel & B-500-S & $\phi(\mathrm{mm})=25$ & $\phi(\mathrm{mm})=20$ \\
\hline $\mathrm{Md}$ & & & 2628,6 KN.m & Sample & Strength (MPa) & \multicolumn{2}{|c|}{ Safety Coefficient } \\
\hline \multicolumn{3}{|c|}{ Dimensions } & $\cdots \cdots \cdots$ & $\mathrm{HA}-30$ & 30 & 1,43 & 1,00 \\
\hline $\mathrm{b}(\mathrm{m})$ & & 0,55 & . & HAR & 95,5 & 1,67 & 1,10 \\
\hline$a(m)$ & & 1,25 & & H-CNT-1 & 90,6 & 1,66 & 1,09 \\
\hline$r(m)$ & & 0,043 & & H-CNT-2 & 89 & 1,66 & 1,06 \\
\hline \multicolumn{3}{|c|}{ Reinforced } & & $\mathrm{H}-\mathrm{CNT}-3$ & 84,8 & 1,66 & 1,09 \\
\hline nh & nv & 5 & $\ldots \ldots \ldots$ & H-CNT-4 & 87,5 & 1,66 & 1,09 \\
\hline
\end{tabular}

\section{Conclusions}

As shown in Table 4, the workability of the cement mortar specimens with CNT considerably diminished from the HAR, because the dispersion of CNT in the cementitious matrix is not entirely homogeneous. The CNT functionalized with $\mathrm{OH}$ groups with high purity and a high degree of functionalization, improve the behavior of specimens of cement pastes and mortars around $20 \%$ as long as the process of dispersing them on the matrix has followed the steps necessary to reach its goal.

So far, the applicability of the CNT due to its high cost is reduced especially at laboratory tests to understand the behavior and the modifications that produces a structural level on the matrix. Although new publications are appearing about the effects of the results remain inconsistent, finding a pattern to determine in advance the impact that will produce the different structures in the cementitious matrix. The high cost of these structures makes the use of the so-called industrial grade products necessary, with a higher percentage of impurities and a lower degree of 
functionalization, thus giving rise to a loss of reinforcing effect that these structures possess, as well as a lack of thoroughness and accuracy of the kneading work, also making it lose the beneficial effects these nanotubes can have over the cementitious matrix.

As seen in Table 6, after making the dimensioning of the structural elements, we do not perceive a noticeable difference between HSC and CNT concretes. For the practical case of sizing the portal, it is observed that it can cause a decrease in sections of steel comparing conventional concrete with high strength concrete, while the dimensions with specimens of cement mortar with CNT are virtually the same as those of HSC, so it is economically unprofitable to use cement mortars with CNT.

It can be said that, given the above mentioned the results, for the time being, in concrete with CNT, increase their Cs, but only if the results of workability and sizing are analyzed. CNT concretes have considerably lower workability than that of HSC. Therefore, and so far, we only consider appropriate the use of CNTs as mechanical reinforcing agents, for small laboratory scale samples. It is necessary to scrutinize the method of dispersion of CNT in cementitious matrices in order to obtain a superior workability.

\section{Acknowledgement}

The authors would like to thank Lucía Redondo and Mercedes Castro, researchers of the Technical University of Madrid, for their work and contribution to this paper. Also appreciate the help and cooperation of the OHL Group, and particularly the contribution of Elsan Laboratories.

\section{References}

Campillo, I., Dolado, J. S., \& Porro, A. (2004). High-performance nanostructured materials for construction. Special Publication-Royal Society of Chemistry, 292, 215-226.

Comisión Permanente del Hormigón. (2011). EHE-08 - Instrucción de Hormigón Estructural.

Comisión Permante de Normas Sismoresistentes. Ministerio de Fomento. (2002). Norma de Construcción Sismorresistente Española.

De la Rosa, R. H. (2004). Hormigones de alta resistencia para pavimentos tipo whitetopping delgado. Revista de La Construcción, 3(2), 14-26.

De Volder, Michael F. L. Sameh H. Tawfick, R. H. B. and, \& Hart, A. J. (2013). Carbon Nanotubes: Present and Future Commercial Applications. Science, 339, 535-539. http://doi.org/10.1126/science.1222453

Ferro, G., Tulliani, J., \& Musso, S. (2011). Carbon nanotubes cement composites. Convegno IGF XXI, 18, 49-59. http://doi.org/10.3221/IGFESIS.18.04

Georgakilas, V., Kordatos, K., Prato, M., Guldi, D. M., Holzinger, M., \& Hirsch, A. (2002). Organic Functionalization of Carbon Nanotubes. Journal of American Chemical Society, 124(5), 760-761.

lijima, S. (1991). Helical microtubules of graphitic carbon. Nature, 354(6348), 56-58. http://doi.org/10.1038/354056a0

Kroto, H. W., Heath, J. R., O’Brien, S. C., Curl, R. F., \& Smalley, R. E. (1985). C 60: buckminsterfullerene. Nature, 318 , 162. http://doi.org/10.1038/318162a0

Li Wang, Pei Ming, Zhao, Xiaohua, G. Y. (2005). Mechanical behavior and microstructure of cement composites incorporating surface-treated multiwalled carbon nanotubes. Carbon, 43(6), 1239-1245.

Li, G. Y., Wang, P. M., \& Zhao, X. (2007). Pressure-sensitive properties and microstructure of carbon nanotube reinforced cement composites. Cement \& Concrete Composites, 29(5), 377-382. http://doi.org/10.1016/j.cemconcomp.2006.12.011

Lukyanovich, V. M. R. L. V. (1952). The structure of carbon forming in thermal decomposition of carbon monoxide on an iron catalyst. Soviet Journal of Physical Chemistry, 26, 88-95.

Makar, J., \& Beaudoin, J. (2003). Carbon nanotubes and their application in the construction industry. Nanotechnology, 331-341. http://doi.org/10.1039/9781847551528-00331

Martínez, M. R., Ganzer, J. R., \& Huertas, M. C. (2007). Future and current applications of carbon nanotubes, material linnovation, aerospace technology and nanotechnology.

Min Feng Yu, S., B., Arepalli, S., \& Ruoff, R. S. (2000). Tensile Loading of Ropes of Single Wall Carbon Nanotubes and their Mechanical Properties. Physical Review Letter, 84, 5552.

Popov, V. N. (2004). Carbon nanotubes: properties and application. Materials Science and Engineering: R: Reports, 43(3), 61-102. http://doi.org/10.1016/j.mser.2003.10.001

Saito, S., Dresselhaus, G., \& Dresselhaus, M. S. (1998). Physical Properties of Carbon Nanotubes. Carbon Nanotubes (Vol. 3). http://doi.org/10.1063/1.56490 
Sobolkina, A., Mechtcherine, V., Khavrus, V., Maier, D., Mende, M., Ritschel, M., Leonhardt, A., (2012). Dispersion of carbon nanotubes and its influence on the mechanical properties of the cement matrix. Cement and Concrete Composites, 34(10), 1104-1113. http://dx.doi.org/10.1016/j.cemconcomp.2012.07.008.

VV.AA. (2016). Código Técnico de la Edificiación (CTE). http://doi.org/CTE-DB-SE

Wansom, S., Kidner, N. J., Woo, L. Y., \& Mason, T. O. (2006). AC-impedance response of multi-walled carbon nanotube/cement composites. Cement and Concrete Composites, 28(6), 509-519. http://doi.org/10.1016/j.cemconcomp.2006.01.014

Williams, J. H. (2008). Employee engagement: Improving participation in safety. Professional Safety, (December), 18-23.

Yu, M. (2000). Strength and Breaking Mechanism of Multiwalled Carbon Nanotubes Under Tensile Load. Science, 287(5453), 637-640.

Zheng, L. X., O’Connell, M. J., Doorn, S. K., Liao, X. Z., Zhao, Y. H., Akhadov, E. A., ... Zhu, Y. T. (2004). Ultralong single-wall carbon nanotubes. Nature Materials, 3(10), 673-676. http://doi.org/10.1038/nmat1216

Zhu, H. W., Xu, C. L., Wu, D. H., Wei, B. Q., Vajtai, R., \& Ajayan, P. M. (2002). Direct synthesis of long single-walled carbon nanotube strands. Science, 296(5569), 884-886. http://doi.org/10.1126/science.1066996 